\title{
Production of diploid and triploid offspring by inbreeding of the triploid planarian Dugesia ryukyuensis
}

\author{
Kazuya Kobayashi • Hirotsugu Ishizu • \\ Sachiko Arioka • Jocelyn Padilla Cabrera • \\ Motonori Hoshi • Midori Matsumoto
}

Published online: 1 April 2008

(C) Springer-Verlag 2008

\section{Erratum to: Chromosoma \\ DOI 10.1007/s00412-008-0148-6}

The legend to Fig. 4 should read as follows:

Fig. 4 a Five karyotypes of the offspring based on the chromosome 4 pattern. Di- 1 and Di-2 offspring were diploid. Tri-1, Tri-2 and Tri-3 offspring were triploid. b The FISH pattern of chromosome 4. The subtelocentric chromosome 4 of the offspring identified by FISH for $18 \mathrm{~S}$ rDNA (marked*) a

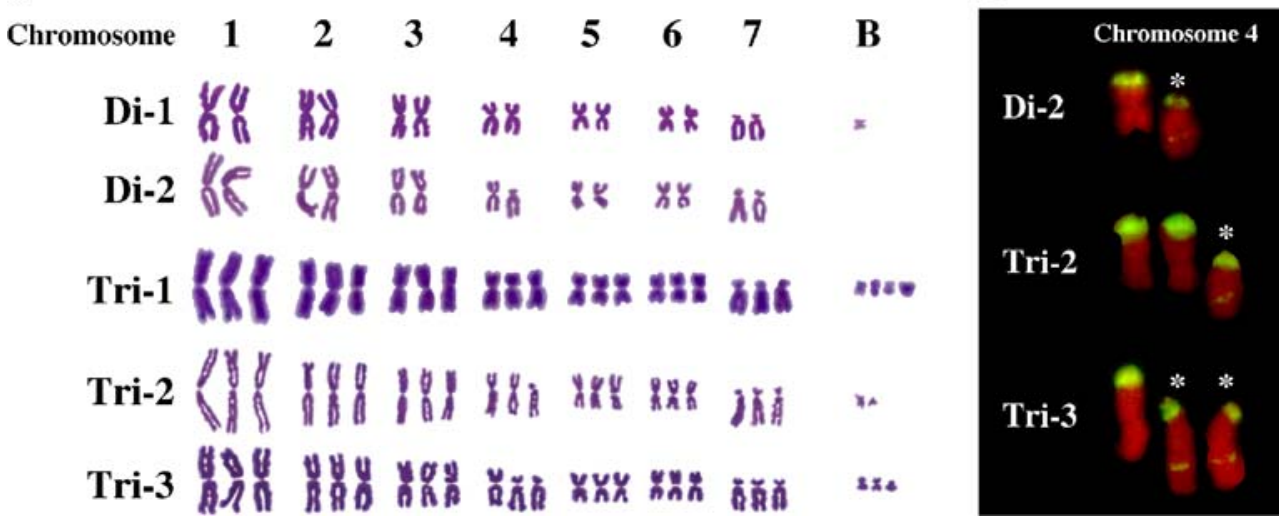

The online version of the original article can be found at http://dx.doi. org/10.1007/s00412-008-0148-6.

K. Kobayashi $\cdot$ H. Ishizu $\cdot$ S. Arioka $\cdot$ M. Hoshi $\cdot$

M. Matsumoto $(\square)$

Department of Biosciences and Informatics,

Keio University, Hiyoshi 3-14-1,

Kouhoku-ku, Yokohama 223-8522, Japan

e-mail: mmatsumo@bio.keio.ac.jp

K. Kobayashi $\cdot$ H. Ishizu $\cdot$ S. Arioka $\cdot$ M. Hoshi $\cdot$ M. Matsumoto Center for Life Science and Technology,

Keio University, Hiyoshi 3-14-1,

Kouhoku-ku, Yokohama 223-8522, Japan

J. Padilla Cabrera

Institute of Biology, University of the Philippines, Diliman,

Quezon City 1101 Manila, Philippines
Present address:

K. Kobayashi

Animal Evolutionary Ecology, Zoological Institute,

University of Tübingen, Auf Der Morgenstelle 28,

72076 Tübingen, Germany

Present address:

M. Hoshi

University of the Air, 2-11, Wakaba,

Mihamu-ku, Chiba 261-8586, Japan

Present address:

J. Padilla Cabrera

Nueva Vizcaya State University, Bayombong,

Nueva Vizcaya 3700, Philippines 